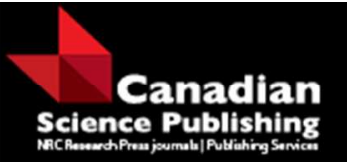

Canadian Journal of Forest Research Revue canadienne de recherche forestière

\title{
Automated Prediction of Extreme Fire Weather from Synoptic Patterns in Northern Alberta, Canada.
}

\begin{tabular}{|r|l|}
\hline Journal: & Canadian Journal of Forest Research \\
\hline Manuscript ID & cjfr-2017-0063.R1 \\
\hline Danuscript Type: & Article \\
\hline Complete List of Authors: & $\begin{array}{l}\text { Lagerquist, Ryan; University of Oklahoma, School of Meteorology } \\
\text { Flannigan, Mike; University of Alberta, Renewable Resources } \\
\text { Wang, Xianli; Canadian Forest Service, Great Lake Forestry Centre } \\
\text { Marshall, Ginny; University of Alberta, Renewable Resources }\end{array}$ \\
\hline $\begin{array}{r}\text { Is the invited manuscript for } \\
\text { consideration in a Special }\end{array}$ & wildland fire, fire danger, weather, SOM, fire regime \\
\hline Issue? : & N/A \\
\hline &
\end{tabular}

SCHOLARONE ${ }^{\text {m }}$

Manuscripts 
1 Automated prediction of extreme fire weather from synoptic patterns in northern Alberta,

2 Canada.

3 Ryan Lagerquist ${ }^{1}$, Mike D. Flannigan ${ }^{2}$, Xianli Wang $^{3}$, Ginny A. Marshall ${ }^{2}$

4

$5{ }^{1}$ School of Meteorology, University of Oklahoma, Norman, Oklahoma, United States, 73019

$6{ }^{2}$ Department of Renewable Resources, University of Alberta, Edmonton, Alberta, Canada T6G

$7 \quad 2 \mathrm{H} 1$

$8{ }^{3}$ Canadian Forest Service, Great Lakes Forestry Center, Sault Ste. Marie, Ontario, Canada P6A

$9 \quad 2 \mathrm{E} 5$

10

11 Suggested running head:

12 "Fire-weather prediction from synoptic patterns"

13

14 Corresponding author:

15 Mike Flannigan (email: mike.flannigan@ulaberta.ca)

16

17 Additional keywords: Fire danger, Fire regimes, SOM, Weather

18 


\section{Abstract}

22 Wildfires burn an average of 2 million hectares per year in Canada, most of which can be

23 attributed to only a few days of severe fire weather. These "spread days" are often associated

24 with large-scale weather systems. We used extreme threshold values of three Canadian Fire

25 Weather Index System (CFWIS) variables - the Fine Fuel Moisture Code (FFMC), Initial Spread

26 Index (ISI), and Fire Weather Index (FWI) - as a proxy for spread days. Then we used self-

27 organizing maps (SOMs) to predict spread days, with sea-level pressure and 500-hPa

28 geopotential height as predictors. SOMs require many input parameters, and we performed an

29 experiment to optimize six key parameters. For each month of the fire season (May - August),

30 we also tested whether SOMs perform better when trained with only one month or with

31 neighbouring months as well. Good performance (AUC of 0.8) was achieved for FFMC and ISI,

32 while nearly good performance was achieved for FWI. To our knowledge, this is the first study

33 to develop a machine-learning model for extreme fire weather that could be deployed in real-

34 time. 


\section{$40 \quad 1 . \quad$ Introduction}

41 Canada experiences an average of 8000 wildfires per year, burning approximately 2

42 million hectares (Flannigan et al. 2009). Most of this area is burned by relatively few large fires.

43 Stocks et al. (2002) found that fires burning $\geq 200$ ha are responsible for $97 \%$ of the area burned,

44 but only $3 \%$ of the total number of fires, in Canada. These fires are usually associated with a

45 prolonged rain-free period followed by high winds, which create ideal conditions for both fire

46 ignition and spread (Shabbar et al. 2011; Skinner et al. 2002). A large percentage of the area is

47 burned in just a few days with such weather conditions (Rothermel et al. 1994; Flannigan and

48 Wotton 2001; Scotto et al. 2014). These days are called "spread-event days" (Parisien et al.

49 2005; Podur and Wotton 2011), or "spread days" (Wang et al. 2014b), and can be used to

50 estimate potential fire danger (Parisien et al. 2013; Wang et al. 2015; Wang et al. 2016). Thus,

51 predicting the spatial and temporal occurrence of spread days over a large area would be a

52 valuable tool for fire management and prediction.

53 Skinner et al. (1999) show that extreme fire weather is favoured by certain large-scale

54 weather patterns ("synoptic patterns") in the mid-troposphere (at the 500-hPa pressure level,

55 which is usually 5-6 km above sea level). Specifically, extreme fire weather is common under a

56 strong longwave ridge (high-pressure axis with wavelength of $\sim 1000 \mathrm{~km}$ ), during the breakdown

57 of a longwave ridge, and in the eastern sector of an upper-level shortwave trough (low-pressure

58 axis with wavelength of $\sim 200 \mathrm{~km})$. Longwave ridges are often associated with warm, dry

59 weather, which allows the fuels to dry. Meanwhile, shortwave troughs are often associated with 
60 strong wind, which can cause existing fires to spread rapidly. Also, shortwave troughs are

61 sometimes associated with thunderstorms, which can provide an ignition source (lightning).

62 However, these relationships between synoptic weather and wildfire are non-linear and high-

63 dimensional, which means that they cannot be easily modeled by traditional statistical methods

64 (e.g., linear regression). More sophisticated methods are required.

65 Neural networks (Cheng and Titterington 1994) are well known for their ability to learn

66 non-linear relationships. Self-organizing maps (SOMs), a type of neural network, are also well

67 suited to handle high-dimensional data (e.g., gridded meteorological data). SOMs have been

68 used successfully in many meteorological studies, such as attribution of extreme events to

69 synoptic patterns (Cavazos 2000; Nishiyama et al. 2007; Schuenemann et al. 2009) and

70 predicting changes in the occurrence of synoptic patterns under climate change (Schuenemann

71 and Cassano 2009, 2010). In most of these cases, the predictors were synoptic pressure fields,

72 because pressure is well forecast by numerical weather prediction (NWP) models (Kanamitsu et

73 al. 2002; Colle et al. 2003; Krishnamurti et al. 2003; Hamill et al. 2013). Thus, we hypothesized

74 that by applying a SOM to forecast pressure fields, we could produce good fire-weather

75 forecasts. Specifically, we used sea-level pressure (SLP) and 500-hPa geopotential height

76 (H500) as predictors.

77 Fire weather in Canada is measured by the empirically based Canadian Fire Weather

78 Index System (CFWIS) (Van Wagner 1987), which is a key component of the Canadian Forest

79 Fire Danger Rating System (CFFDRS) (Stocks et al. 1989; Taylor and Alexander 2006). The

80 CFWIS consists of six indices, calculated from observations of four weather variables at 1200

81 local standard time (LST): 1.5-metre air temperature, 1.5-metre relative humidity, 10-metre wind

82 speed, and precipitation in the last 24 hours. Of the six CFWIS indices, there are three fuel- 
83 moisture codes and three potential-fire-behaviour indices. The fuel-moisture codes - Fine Fuel

84 Moisture Code (FFMC), Duff Moisture Code (DMC), and Drought Code (DC) - are proxies for

85 fuel moisture in three layers of the forest floor. The potential-fire-behaviour indices - Initial

86 Spread Index (ISI), Build-up Index (BUI), and Fire Weather Index (FWI) - are calculated from

87 the fuel-moisture codes. These are proxies for the rate of fire spread, amount of combustible

88 fuel, and overall fire intensity, respectively.

89 Here we use SOMs to predict extreme fire weather in northern Alberta, where wildfires

90 are common and weather conditions have been monitored for decades. SOMs were trained on

91 SLP and H500 fields to produce "map types," or typical composite SLP-H500 fields; then a fire-

92 weather climatology was created for each map type. This conditional climatology involves

93 statistics of the three dependent variables: FFMC, ISI, and FWI. Our main objectives were to (a)

94 develop a general framework for using SOMs to predict fire weather and (b) create a set of

95 calibrated SOMs for predicting extreme fire weather in northern Alberta.

96

\section{2. Data and methods}

98 2.1. Study area

99 Our main study area was northern Alberta (Figure 1(a)). Throughout Alberta between

1001961 and 2014, wildfires burned an average of 147800 ha per year, with a minimum of 1750 ha

101 in 1962 and maximum of 1357190 ha in 1981 (Blouin et al. 2016). Most of these fires occurred

102 in the northern part of the province, which is heavily forested (Stocks et al. 2002).

103 To eliminate edge effects, we buffered northern Alberta with parts of western

104 Saskatchewan, eastern British Columbia, and the southern Northwest Territories. Thus, the full

105 study area reaches $53-63^{\circ} \mathrm{N}$ and $108-122^{\circ} \mathrm{W}$ (Figure 1(a)). This area consists mainly of two 
106 ecozones (Ecological Stratification Working Group 1996), the Taiga Plains in the northwest and

107 Boreal Plains elsewhere (Figure 1(b)).

108

109 2.2. Data sources

110 2.2.1. Dependent variables

111 We used three CFWIS indices as dependent variables: FFMC, ISI, and FWI. These are

112 proxies for the probability of fire ignition, potential fire intensity, and potential growth rate

113 respectively (Van Wagner 1987). Thresholds of 91 for FFMC, 8.7 for ISI, and 19 for FWI were

114 used to define extreme fire weather (Table 1). FFMC of 91 (corresponding to a moisture content

115 of $10 \%$ ) is a reasonable threshold for vigorous fire spread (Wotton 2009). The thresholds for ISI

116 (8.7) and FWI (19) are also linked to active spread days in Canada (Podur and Wotton 2011).

117 CFWIS indices were calculated from weather variables observed at 1200 LST, provided by

118 Environment Canada (EC) (2015a) and Alberta Agriculture and Forestry (AAF) (2015). The EC

119 (AAF) dataset contains 560 (318) stations in our study area, covering 1953 - 2007 (1975 -

120 2009). See Figure 1(a) for station locations.

121 For the EC dataset, CFWIS indices were calculated using the R function $\mathrm{fwi}$ (Wang et

122 al. 2017). For the AAF dataset, CFWIS indices were already calculated. Inputs for the CFWIS

123 indices should include accumulated precipitation from 1200-1200 LST, but precipitation in the

124 EC dataset is measured from $0600-0600$ UTC (2300 - 2300 LST in northern Alberta). Thus,

125 the offset between the two measurement periods was 11 hours. However, our model focuses on

126 extreme fire weather, which usually occurs only after a prolonged dry period. Thus, the 11-hour

127 offset was an issue only when precipitation occurred at the end of a prolonged dry period. 


\subsubsection{Predictor variables}

130 In datasets with many grid cells (as in Figure 1(b)), the dimensionality increases quickly

131 with the number of variables. For example, if there are 500 grid cells, adding one variable

132 increases the dimensionality by 500. High dimensionality leads to longer processing time, more

133 memory usage, and often overfitting. These symptoms are part of the "curse of dimensionality".

134 In similar studies (where SOMs were trained with many grid cells), only $1-3$ variables were

135 used (e.g., Hewitson and Crane 2002; Reusch et al. 2005; Nishiyama et al. 2007; Schuenemann

136 et al. 2009; Schuenemann and Cassano 2009, 2010). In this study we used two predictor

137 variables, the aforementioned SLP and H500.

138 SLP and H500 drive the surface and upper-level winds, respectively, which allows them to

139 significantly impact surface weather conditions. Low pressure generally leads to cool and wet

140 (poor burning) conditions, while high pressure generally leads to warm and dry (good burning)

141 conditions. For example, as mentioned in Section 1, longwave pressure ridges often lead to

142 warm and dry conditions, which promote the drying of fuels.

143 SLP and H500 fields were downloaded from the North American Regional Reanalysis

144 (NARR) (Mesinger et al. 2006). The NARR is an atmospheric and hydrological dataset, created

145 using output from the National Centers for Environmental Prediction (NCEP) - Department of

146 Energy (DOE) Global Reanalysis, the NCEP Eta model, the Noah land-surface model, and

147 observed precipitation. NARR data are provided on a 32-km grid with 3-hour time steps. We

148 used every fourth grid cell (every second grid cell in both $x$ - and $y$-directions), which increased

149 the grid spacing to $64 \mathrm{~km}$. This helped to mitigate high-dimensionality problems.

$151 \quad 2.3 . \quad$ Data-processing 
153 Synoptic-scale wind is driven by horizontal pressure gradients, rather than single point

154 values. Thus, we trained the SOMs with horizontal pressure gradients. These were calculated by

155 the finite-difference equations below.

$$
\begin{aligned}
& \frac{\partial Q_{i, j}}{\partial x}=\frac{Q_{i+1, j}-Q_{i-1, j}}{2 \Delta x} \\
& \frac{\partial Q_{i, j}}{\partial y}=\frac{Q_{i, j+1}-Q_{i, j-1}}{2 \Delta y}
\end{aligned}
$$

$158 Q$ is the relevant variable (SLP or H500); $Q_{k, m}$ is the value at grid cell $(k, m)$; and $\Delta x$ and $\Delta y$ are

159 the zonal and meridional grid spacings, respectively (both $64 \mathrm{~km}$ for our data). The result is four

160 gradient components at each grid cell. Thus, taking the gradient doubles the number of

161 variables.

162 Because the predictor and dependent variables have different time resolutions (3 and 24

163 hours, respectively), we averaged the predictors for each day over 24 hours (eight time steps).

164 This averaging was complicated by two factors: (a) CFWIS indices are time-referenced in LST,

165 while predictors are time-referenced in UTC; (b) although CFWIS indices are based on weather

166 conditions observed at 1200 LST, they are calculated to represent late-afternoon burning

167 conditions (Van Wagner 1987). Late afternoon is $1500-1800$ LST, or $2200-0100$ UTC in

168 northern Alberta, so CFWIS indices in northern Alberta are valid for approximately 0000 UTC.

169 Thus, for each day $D$, we averaged predictors from the last eight time steps before 0000 UTC

170 (0000 UTC, $0300 \mathrm{UTC}, \ldots, 2100 \mathrm{UTC}$ of day $D-1)$. This allowed predictors and CFWIS

171 indices to be linked in time. Averaging was done independently for each gradient component at 172 each grid cell. 
173 Thus, predictor variables were transformed in two ways: gradient calculation and time-

174 averaging. In general, the order of operations would matter. However, since a linear finite-

175 difference operator (Equation 1) was used, the average gradient is the gradient of the average.

176 The three datasets (EC, AAF, and NARR) cover different time periods. We used the

177 common years, 1979 - 2007, for training and testing.

179 2.4. Using SOMs to predict extreme fire weather: basic ideas

180 At the simplest level, a SOM is a two-dimensional array of neurons. Each neuron has

181 two properties: its position in the array, and a "codebook vector" or "map type," which is a

182 pattern found in the training data. Each training example is a predictor field, consisting of the

183 four gradient components at each grid cell in Figure 1(b). The dimensions of the neuron layer

184 and predictor fields are independent. However, the dimensions of a map type equal the

185 dimensions of a predictor field (252 grid cells by 4 variables). As the SOM is trained, each map

186 type becomes more similar to a subset of the training data; in other words, map types are

187 "adjusted to" the training data. However, if the SOM is trained for too long, it will overfit and

188 generalize poorly to new data.

189 After training the SOM, map types are correlated with fire weather. In other words, a

190 conditional climatology is created for each dependent variable, given each map type. Assuming

191 that (a) conditional climatologies hold for new data and (b) good forecasts of SLP and H500 are

192 available, map types can be used to make good fire-weather forecasts on new data.

193 The fire season in northern Alberta is roughly May through August (Skinner et al. 2002).

194 Thus, we trained SOMs for one month at a time, which allowed them to implicitly account for

195 seasonality (e.g., the same synoptic pressure pattern might cause different fire-weather 
196 conditions in May than in August). Lastly, to control for overfitting, the data for each SOM were

197 split into a test set $(1980,1985,1990,1995,2000,2005)$ and training set (the other 22 years).

198 For more details on using SOMs to predict fire weather, see supplementary material.

\subsection{Forecast evaluation}

SOMs were evaluated with receiver operating characteristic (ROC) curves (Metz 1978).

For each SOM and each dependent variable $V$, the ROC curve is created as follows.

1. Generate forecasts of extreme-value probability ( $\hat{p}_{\text {extreme }}$ in Equation 4(a) of supplementary material) for the test set (over all grid cells $G$ and dates $D$ ).

2. Find unique values of $\hat{p}_{\text {extreme }}$ ("thresholds"). For each threshold $p^{*}$, call any $\hat{p}_{\text {extreme }} \geq p^{*}$ a "yes" forecast and any $\hat{p}_{\text {extreme }}<p^{*}$ a "no" forecast. Then calculate the true-positive rate (TPR) and false-positive rate (FPR).

3. Plot TPR-FPR pairs on a graph (as in Figure 2).

$$
\begin{aligned}
T P R & =\frac{\# \text { of true positives }}{\# \text { of actual positives }} \\
F P R & =\frac{\# \text { of false positives }}{\# \text { of actual negatives }}
\end{aligned}
$$

211 For each ROC curve, area under the curve (AUC) was used to measure performance.

212 AUC varies from 0.0 to 1.0, and higher values are considered better. Commonly used thresholds

213 for a "fair" and "good" predictor are 0.7 and 0.8, respectively (Luna-Herrera et al. 2003; Muller

214 et al. 2005; Mehdi et al. 2011).

\subsection{Tuning (calibration of input parameters)}

217 Using the framework developed in supplementary material, we trained SOMs with

218 various input parameters, with the goal of optimizing parameters for each dependent variable and 
219 month. However, it was impossible to experiment with all parameters, so some were fixed using

220 a priori reasoning. These "controlled parameters" are listed in Table 2, while "experimental

221 parameters" are listed in Table 3.

222 For two of the six experimental parameters, values were set by a coefficient rather than

223 directly, following suggestions in SOM_PAK. The first is number of epochs, which was set using

224 Equations 3.

$$
N_{e}^{\text {fine }}=d \frac{N_{\text {neurons }}}{N_{\text {training }}}
$$

$227 N_{e}^{\text {rough }}\left(N_{e}^{\text {fine }}\right)$ is the number of epochs for rough- (fine-) tuning; $d$ is a coefficient; $N_{\text {neurons }}$ is the 228 number of neurons; and $N_{\text {training }}$ is the number of training examples. The second is initial

229 neighbourhood radius, which was set using Equations 4.

$$
\begin{gathered}
\sigma_{0}^{\text {rough }}=c_{1} \max \left(N_{\text {rows }}, N_{\text {cols }}\right) \\
\sigma_{0}^{\text {fine }}=c_{2} \sigma_{0}^{\text {rough }}
\end{gathered}
$$

$232 \sigma_{0}^{\text {rough }}\left(\sigma_{0}^{\text {fine }}\right)$ is the initial radius for rough- (fine-)tuning; $c_{1}$ and $c_{2}$ are coefficients; $N_{\text {rows }}$ is the 233 number of rows, and $N_{\text {cols }}$ is the number of columns, in the neuron array.

\subsubsection{Tuning, Phase One}

For each dependent variable, we trained SOMs with all 5760 combinations of the six

237 experimental parameters. In this phase SOMs were trained for July only, without the use of

238 neighbouring months. This decreased processing time and allowed all 5760 combinations to be

239 tested. By tuning parameters for July only, we assumed that optimal parameters (a) are similar

240 for a SOM trained with or without neighbouring months and (b) are similar for all months in the 
241 fire season.

243 2.6.2. Tuning, Phase Two

244 For each dependent variable, the top 25 SOMs (those with the best AUCs) from Phase 1

245 were used in Phase 2. Each of the 25 SOMs was trained for all months of the fire season, both

246 with and without neighbouring months. The procedure is as follows, for each dependent variable $247 \quad V$.

248 1. Find the top 25 SOMs from Phase 1. Call these $S^{*}$.

2492 . For each $S^{*}$ and each month (May - August), retrain the SOM twice: once with

250 neighbouring months, once without. Keep all other parameters as they were in Phase 1.

251 3. For each month (May - August), find the best SOM from step 2.

252 The result of this experiment is one chosen SOM for each dependent variable and month.

$254 \quad$ 3. Results

255 3.1. Phase One

256 Figure 2(a) shows the best ROC curve for each dependent variable. The AUCs were

257 approximately 0.782 for FFMC, 0.765 for ISI, and 0.717 for FWI. Thus, SOMs trained with July

258 only achieved nearly good performance for FFMC and ISI, but only fair performance for FWI.

259 For each dependent variable, Figure 3 shows the distribution of experimental parameter

260 for the best 25 SOMs. In general, the best $d$-coefficients were 25 and 100, leading to the fewest

261 and most epochs respectively. The best neighbourhood functions were bubble and

262 Epanechnikov (the two non-Gaussian functions), for FFMC, the two Gaussian functions for ISI, 
263 and Epanechnikov for FWI. For neighbourhood radius, there was no clear winner for FFMC and

264 ISI; the best combination for FWI was $c_{1}=c_{2}=1 / 4$, which leads to the smallest neighbourhood

265 radii. For the gradient-distance exponent, there was also no clear winner for FFMC and ISI;

266 higher values were strongly preferred for FWI. $K$-means was clearly the best clustering method

267 for all dependent variables. Lastly, fewer map types were preferred for FFMC and ISI; there was

268 no clear winner for FWI.

\section{3.2. Phase Two}

271 For the chosen SOMs, Figures 2(b-e) show ROC curves and Table 4 shows the

272 distribution of experimental parameters. The top AUC was 0.837 for FFMC (August), 0.802 for

273 ISI (August), and 0.782 for FWI (May). Thus, good (nearly good) performance was achieved for

274 FFMC and ISI (FWI). In general, performance was worse in the middle of the fire season (June

275 and July, as opposed to May and August).

Figure 4 is to Phase 2 as Figure 3 is to Phase 1. However, SOMs in Figure 4 were

277 selected in a slightly different way. For each dependent variable and month, we selected the top

278 five SOMs trained with neighbouring months and the top five without. Otherwise, many of the

279 SOMs selected would have been trained on the same time period, which would decrease the 280 generality of the results.

282 Phase 2 were 50 for FFMC, 25 for ISI and FWI - which suggests that better performance occurs

283 with fewer epochs. In contrast, the best values in Phase 1 were 25 and 100, which suggested

284 optima at both ends of the spectrum. For neighbourhood function and radius, Phase 2 results

285 were inconclusive for all dependent variables. For the gradient-distance exponent, higher values 
286 were preferred for all dependent variables in Phase 2. This is consistent with, but stronger than,

287 Phase 1 results. Lastly, the best number of map types in Phase 2 was $\leq 20$ for FFMC (consistent

288 with Phase 1), $\geq 60$ for ISI (opposite of Phase 1), and $\leq 20$ for FWI (inconclusive in Phase 1).

289 For all dependent variables in June and FWI in August, the best SOMs were those trained

290 with neighbouring months. Also, for these four variable-month pairs, nearly all SOMs trained

291 with neighbouring months were better than all SOMs trained without. For the other eight

292 variable-month pairs, the opposite was true.

293 Based on these results, recommended values of experimental parameters are given in

294 Table 5.

295 4. Discussion and conclusions

296 The chosen SOMs were consistently good or nearly good predictors of FFMC and ISI,

297 but only fair predictors of FWI. As discussed in Van Wagner (1987), FFMC and ISI respond

298 more quickly to changes in weather conditions than does FWI. This is because the FWI formula

299 involves BUI (a proxy for combustible fuel), which has a much longer response time. To

300 account for this, we made the $e$-folding time and maximum lags longer ( 1 and 8 days,

301 respectively) for FWI. However, FWI predictions still had the worst performance of all three

302 variables. Perhaps this is because FWI's response to weather conditions does not follow the

303 exponential decay assumed in Equations 4 of the supplement, or perhaps the values chosen for $e$ -

304 folding time and maximum lag were inappropriate.

305 Inferior SOM performance in June and July was probably due to increased thunderstorm

306 activity in these months. Thunderstorms often produce heavy rain and strong winds, both of

307 which significantly impact fire weather. However, thunderstorms are subsynoptic-scale

308 phenomena, which makes them harder to predict with synoptic weather patterns (e.g., pressure 
309 fields at 64-km resolution). This shortcoming could potentially be improved by (a) downloading

310 predictor fields from a higher-resolution model or (b) using additional variables with a stronger

311 relation to thunderstorm activity, such as convective available potential energy (CAPE).

312 However, these approaches would increase the number of (a) grid cells or (b) variables, which

313 would increase the risks associated with high dimensionality (Section 2.2.2).

314 The best SOMs for June were those trained with neighbouring months, which suggests

315 that the relationship between predictors (SLP and H500) and fire weather is fairly constant from

316 May through July. This also suggests that other predictors of fire weather (those not included in

317 the SOMs) are fairly constant over the three months. For May, July, and August, the best SOMs

318 were those trained without neighbouring months, which suggests that non-included predictors

319 (e.g., temperature and humidity) changed significantly over the neighbouring months. This

320 result was unexpected, since temperature and humidity in northern Alberta change more from

321 May - July (the neighbours of June) than, for example, from June - August (the neighbours of

322 July). For example, see climate normal for Athabasca, Fort McMurray, Grande Prairie, and High

323 Level (Environment Canada 2015b). Perhaps July results worsened with neighbouring months

324 simply because July has more thunderstorm activity, so fire weather in July is less dependent on 325 synoptic patterns than in neighbouring months.

326 Previous machine-learning studies in fire weather have attempted to predict only human-

327 caused fire ignition (Cunningham and Martell 1973; Martell et al. 1987, 1989; Garcia et al.

328 1995; Wotton et al. 2003), only lightning-caused fire ignition (Krawchuk et al. 2009), large-fire

329 ignition (both lightning- and human-caused) (Preisler et al. 2004; Preisler and Westerling 2007;

330 Bradstock et al. 2009), or area burned and number of fires (Carvalho et al. 2008). Also, a few

331 studies have related fire activity to synoptic weather patterns, but without explicitly developing a 
332 predictive model. Skinner et al. (1999) used $K$-means clustering to find H500 patterns associated

333 with large fires in Canada, and Crimmins (2006) used SOMs to find 700-hPa height patterns

334 associated with extreme fire weather in the southeastern U.S. Pereira et al. (2005) used linear

335 regression on May - August precipitation and H500 to predict June - September burned area in

336 Portugal. Although they developed a predictive model, it requires data for the first four months

337 of the fire season, which precludes it from real-time use.

338 To the best of our knowledge, this is the first study to develop a fire-weather-prediction

339 model that could be deployed in real-time. We chose to predict fire weather, rather than activity,

340 due to human stochasticity involved in the latter (e.g., human-caused ignition and suppression

341 efforts). Weather is arguably the best predictor of fire activity over time periods of a month or

342 longer (Cary et al. 2006; Abatzoglou and Kolden 2013). Also, NWP-forecast pressure fields and

343 daily CFWIS indices are already ubiquitous in Canadian fire management. Thus, our product

344 could be a useful and easily applied tool for fire-management agencies throughout Canada.

345 However, our models apply only to northern Alberta, so separate SOMs would need to be trained

346 for other regions.

347 Our current SOM approach may have benefits over traditional approaches of predicting

348 extreme fire weather. The standard way of predicting extreme fire weather is to take the forecast

349 values of surface temperature, relative humidity, wind speed and 24-h precipitation and then

350 calculate the FWI System indices. Predicted values of these surface meteorological variables

351 used in the conventional approach are not nearly as accurate as predicted values of SLP and

352 H500. This suggests that SOMs may provide a better and more robust method to flag potential

353 extreme fire-weather events. This could contribute to the development of an early warning

354 system so that fire management agencies could ensure resources are available and in position. 


\section{Acknowledgements}

358 Weather observations and CFWIS indices were provided by Alberta Agriculture and

359 Forestry. Weather observations were also provided by Anthony Liu of Environment Canada.

360 CFWIS indices were calculated with code from Xianli Wang, Alan Cantin, Marc-André Parisien,

361 Mike Wotton, Kerry Anderson, and Mike Flannigan. Renee Beaulac helped prepare the

362 manuscript. This research was funded in part by Alberta Agriculture and Forestry.

\section{References}

364 Abatzoglou J.T., Kolden C.A. (2013) Relationships between climate and macroscale area burned

365 in the Western United States. Int. J. Wildland Fire 22, 1003-1020. doi:10.1071/WF13019

366 Alberta Agriculture and Forestry (2015) Forecasts \& Observations. 14 February 2014. Webpage.

3674 October 2015.

368 Blouin K.D., Flannigan M.D., Wang X., Kochtubajda B. (2016) Ensemble lightning prediction

369 models for the province of Alberta, Canada. Int. J. Wildland Fire 25, 421-432.

$370 \quad$ doi:10.1071/WF15111

371 Bradstock R.A., Cohn J.S., Gill A.M., Bedward M., Lucas C. (2009) Prediction of the probability

372 of large fires in the Sydney region of south-eastern Australia using fire weather. Int. J.

373 Wildland Fire 18, 932 - 943. doi:10.1071/WF08133

374 Carvalho A., Flannigan M.D., Logan K., Miranda A.I., Borrego C. (2008) Fire activity in

375 Portugal and its relationship to weather and the Canadian Fire Weather Index System. Int. J.

$376 \quad$ Wildland Fire 17, 328-338. doi:10.1071/WF07014 
377 Cary G.J., Keane R.E., Gardner R.H., Lavorel S., Flannigan M.D., Davies I.D., Li C., Lenihan

378 J.M., Rupp T.S., Mouillot F. (2006) Comparison of the sensitivity of landscape-fire-

379 succession models to variation in terrain, fuel pattern, climate and weather. Landscape

$380 \quad$ Ecology 21, 121-137. doi:10.1007/s10980-005-7302-9

381 Cavazos T. (2000) Using self-organizing maps to investigate extreme climate events: An

382 application to wintertime precipitation in the Balkans. J.Clim. 13, $1718-1732$.

383 doi:10.1175/1520-0442(2000)013<1718:USOMTI>2.0.CO;2

384 Cheng B., Titterington D.M. (1994) Neural networks: A review from a statistical perspective.

$385 \quad$ Statistical Science 9, 2 - 30.

386 Colle B.A., Olson J.B., Tongue J.S. (2003) Multiseason verification of the MM5. Part I:

387 Comparison with the Eta model over the central and eastern United States and impact of MM5

388 resolution. Weather and Forecasting 18, $431-457$.

389 Crimmins M.A. (2006) Synoptic climatology of extreme fire $\square$ weather conditions across the

390 southwest United States. Int. J. Climatol. 26, 1001 - 1016. doi: 10.1002/joc.1300

391 Cunningham A.A., Martell D.L. (1973) A stochastic model for the occurrence of man-caused

392 forest fires. Can. J. For. Res. 3, $282-287$.

393 Ecological Stratification Working Group (1996) A National Ecological Framework for Canada.

394 Agriculture and Agri-food Canada, Research Branch, Centre for Land and Biological

395 Resources Research, and Environment Canada, State of the Environment Directorate,

396 Ecozone Analysis Branch, Ottawa/Hull.

397 Environment Canada (2015) Climate. 11 February 2015a. Webpage. 4 October 2015.

398 Environment Canada (2015) Station Results - 1981 - 2010 Climate Normals and Averages. 22

399 September 2015b. Webpage. 2 November 2015. 
400 Flannigan M.D., Wotton B.M. (2001) Climate, weather, and area burned. In 'Forest Fires:

401 Behavior \& Ecological Effects'. (Eds EA Johnson, K Miyanish) pp. 351-373. (Academic

$402 \quad$ Press)

403 Flannigan M.D., Krawchuk M.A., de Groot W.J., Wotton B.M., Gowman L.M. (2009)

404 Implications of changing climate for global wildland fire. Int. J. Wildland Fire 18, $483-507$.

405 Garcia C.V., Woodard P.M., Titus S.J., Adamowicz W.L., Lee B.S. (1995) A logit model for

406 predicting the daily occurrence of human caused forest-fires. Int. J. Wildland Fire 5, $101-$

407 111. doi:10.1071/WF9950101

408 Hamill T.M., Bates G.T., Whitaker J.S., Murray D.R., Fiorino M., Galarneau T.J., Zhu Y.,

409 Lapenta W. (2013) NOAA's second-generation global medium-range ensemble reforecast

410 dataset. Bulletin of the American Meteorolog. Soc. 94, 1553 - 1565. doi:10.1175/BAMS-D-

$411 \quad 12-00014.1$

412 Hewitson B.C., Crane R.G. (2002) Self-organizing maps: Applications to synoptic

413 climatology. Climate Res. 22, $13-26$.

414 Kanamitsu M., Kumar A., Juang H-M. H., Schemm J-K., Wang W., Yang F., Hong S-Y., Peng

415 P., Chen W., Moorthi S, Ji M. (2002) NCEP dynamical seasonal forecast system 2000.

416 Bulletin of the American Meteorol. Soc. 83, 1019 - 1037.

417 Kohonen T., Hynninen J, Kangas J., Laaksonen J. (1996) SOM_PAK: The self-organizing map

418 program package. Helsinki University of Technology, Laboratory of Computer and

419 Information Science, Report A31.

420 Krawchuk M.A., Cumming S.G., Flannigan M.D. (2009) Predicted changes in fire weather

421 suggest increases in lightning fire initiation and future area burned in the mixedwood boreal

422 forest. Climatic Change 92, 83 - 97. doi:10.1007/s10584-008-9460-7 
423 Krishnamurti T.N., Rajendran K., Vijaya Kumar T.S.V., Lord S., Toth Z., Zou X., Cocke S.,

424 Ahlquist J.E., Navon I.M. (2003) Improved skill for the anomaly correlation of geopotential

425 heights at $500 \mathrm{hPa}$. Monthly Weather Rev. 131, 1082 - 1102. doi:10.1175/1520-

$426 \quad$ 0493(2003)131<1082:ISFTAC $>2.0 . C O ; 2$

427 Luna-Herrera J., Martinez-Cabrera G., Parra-Maldonado R., Enciso-Moreno J.A., Torres-Lopez

428 J., Quesada-Pascual F., Delgadillo-Polanco R., Franzblau S.G. (2003) Use of receiver

429 operating characteristic curves to assess the performance of a microdilution assay for

430 determination of drug susceptibility of clinical isolates of Mycobacterium tuberculosis. Eur.

431 J. Clin. Microbiol Infect. Dis. 22, 21 - 27. doi:10.1007/s10096-002-0855-5

432 Martell D.L., Otukol S., Stocks B.J. (1987) A logistic model for predicting daily people-caused

433 forest fire occurrence in Ontario. Can. J. For. Res. 17, $394-401$.

434 Martell D.L., Bevilacqua E., Stocks B.J. (1989) Modelling seasonal variation in daily people-

435 caused forest fire occurrence. Can. J. For. Res. 19, $1555-1563$.

436 Mehdi T., Bashardoost N., Ahmadi M. (2011) Kernel smoothing for ROC curve and estimation

437 for thyroid stimulating hormone. Int. J. Environ. Res. Publ. Health. Special Issue, $239-242$.

438 Mesinger F., DiMego G., Kalnay E., Mitchell K., Shafran P.C., Ebisuzaki W., Jovic D., Woollen

439 J., Rogers E., Berbery E.H., Ek M.B., Fan Y., Grumbine R., Higgins W., Li H., Lin Y.,

440 Manikin G., Parrish D., Shi W. (2006) North American regional reanalysis. Bulletin of the

$441 \quad$ American Meteorol. Soc. 87, $343-360$.

442 Metz C.E. (1978) Basic principles of ROC analysis. Seminars in Nuclear Medicine 8, 283 - 298.

443 Muller M.P., Tomlinson G., Marrie T.J., Tang P., McGeer A., Low D.E., Detsky A.S., Gold

444 W.L. (2005) Can routine laboratory tests discriminate between Severe Acute Respiratory 
445 Syndrome and other causes of community-acquired pneumonia? Clinical Infectious

446 Diseases 40, 1079 - 1086. doi:10.1086/428577

447 Nishiyama K., Endo S., Jinno K., Uvo C.B., Olsson J., Berndtsson R. (2007) Identification of

448 typical synoptic patterns causing heavy rainfall in the rainy season in Japan by a Self-

449 Organizing Map. Atmospheric Res. 83, 185 - 200.

450 Parisien M-A., Kafka V.G., Hirsch K.G., Todd J.B., Lavoie S.G., Maczek P.D. (2005) Mapping

451 wildfire susceptibility with the BURN-P3 simulation model. Canadian Forest Service,

452 Northern Forestry Centre, Information Report NOR-X-405.

453 Parisien M-A., Walker G.R., Little J.M., Simpson B.N., Wang X., Perrakis D.D.B. (2013)

454 Considerations for modeling burn probability across landscapes with steep environmental

455 gradients: An example from the Columbia Mountains, Canada. Natural Hazards 66, 439-462.

456 doi:10.1007/s11069-012-0495-8

457 Pereira M.G., Trigo R.M., da Camara C.C., Pereira J.M.C., Leite S.M. (2005) Synoptic patterns

458 associated with large summer forest fires in Portugal. Agric. and For. Meteorol. 129, 11 - 25.

459 doi:10.1016/j.agrformet.2004.12.007

460 Podur J., Wotton M.B. (2011) Defining fire spread event days for fire-growth modelling. Int. J.

$461 \quad$ Wildland Fire 20, 497 - 507. doi: 10.1071/WF09001

462 Preisler H.K., Brillinger D.R., Burgan R.E., Benoit J.W. (2004) Probability based models for

463 estimation of wildfire risk. Int. J. Wildland Fire 13, 133 - 142. doi:10.1071/WF02061

464 Preisler H.K., Westerling A.L. (2007) Statistical model for forecasting monthly large wildfire

465 events in western United States. J. Appl. Meteorol. Climatol. 46, 1020 - 1030.

466 doi:10.1175/JAM2513.1 
467 Reusch D.B., Alley R.B., Hewitson B.C. (2005) Relative performance of self-organizing maps

468 and principal component analysis in pattern extraction from synthetic climatological

469 data. Polar Geography 29, $188-212$.

470 Rothermel R.C., Hartford R.A., Chase C.H. (1994) Fire growth maps for the 1988 Greater

471 Yellowstone Area fires. USDA, Forest Service, Intermountain Research Station, General

472 Technical Report INT-304.

473 San-Miguel-Ayanz J., Carlson J.D., Alexander M., Tolhurst K., Morgan G., Sneeuwjagt R.,

474 Dudley M. (2003) Current methods to assess fire danger potential. In 'Wildland fire danger

475 estimation and mapping: The role of remote sensing data'. (Ed E Chuvieco) pp. $21-62$.

$476 \quad$ (World Scientific)

477 Schuenemann K.C., Cassano J.J., Finnis J. (2009) Synoptic forcing of precipitation over

478 Greenland: Climatology for 1961 - 99. J. Hydrometeorol. 10, 60 - 78. doi:

$479 \quad$ 10.1175/2008JHM1014.1.

480 Schuenemann K.C., Cassano J.J. (2009) Changes in synoptic weather patterns and Greenland

481 precipitation in the 20th and 21st centuries: 1 . Evaluation of late 20th century simulations

482 from IPCC models. J. Geophys. Res.: Atmos. 114, D20113. doi:10.1029/2009JD011705

483 Schuenemann K.C., Cassano J.J. (2010) Changes in synoptic weather patterns and Greenland

484 precipitation in the 20th and 21st centuries: 2 . Analysis of 21 st century atmospheric changes

485 using self-organizing maps. J. Geophys. Res.: Atmos 115, D05108.

486 doi:10.1029/2009JD011706

487 Scotto M.G., Gouveia S., Carvalho A., Monteiro A., Martins V., Flannigan M.D., San-Miguel-

488 Ayanz J., Miranda A.I., Borrego C. (2014) Area burned in Portugal over recent decades: An

489 extreme value analysis. Int. J. Wildland Fire 23, 812 - 824. doi:10.1071/WF13104 
490 Shabbar A., Skinner W., Flannigan M.D. (2011) Prediction of seasonal forest fire severity in

491 Canada from large-scale climate patterns. J. Appl. Meteorol. 50, 785 - 799.

492 Skinner W.R., Stocks B.J., Martell D.L., Bonsal B., Shabbar A. (1999) The association between

493 circulation anomalies in the mid-troposphere and area burned by wildland fire in

494 Canada. Theoretical and Appl. Climatol. 63, 89-105.

495 Skinner W.R., Flannigan M.D., Stocks B.J., Martell D.L., Wotton B.M., Todd J.B., Mason J.A., 496 Logan K.A., Bosch E.M. (2002) A 500 hPa synoptic wildland fire climatology for large 497 Canadian forest fires, 1959-1996. Theoretical and Appl. Climatol. 71, 157 - 169.

498 Stocks B.J., Lynham T.J., Lawson B.D., Alexander M.E., Van Wagner C.E., McAlpine R.S., 499 Dube D.E. (1989) Canadian Forest Fire Danger Rating System: An overview. The Forestry $500 \quad$ Chronicle 65, $258-265$.

501 Stocks B.J., Mason J.A., Todd J.B., Bosch E.M., Wotton B.M., Amiro B.D., Flannigan M.D.,

502 Hirsch K.G., Logan K.A., Martell D.L., Skinner W.R. (2002) Large forest fires in Canada,

5031959 - 1997. J. Geophys. Res.: Atmospheres 107, FFR 5 - 1-FFR 5 - 12.

504 doi:10.7939/R3CF9J70X

505 Taylor S.W., Alexander M.E. (2006) Science, technology, and human factors in fire danger

506 rating: The Canadian experience. Int. J. Wildland Fire 15, 121 - 135. doi:10.1071/WF05021

507 Ultsch A., Mörchen F. (2005) 'ESOM-Maps: Tools for clustering, visualization, and

508 classification with Emergent SOM.' Department of Mathematics and Computer Science,

$509 \quad$ University of Marburg, Research Report 46.

510 Van Wagner C.E. (1987) 'Development and Structure of the Canadian Forest Fire Weather Index

511 System.' Canadian Forestry Service, Forestry Technical Report 35, Ottawa. 
512 Wang X., Parisien M-A., Flannigan M.D., Parks S.A., Anderson K.R., Little J.M., Taylor

513 S.W.(2014b) The potential and realized spread of wildfires across Canada. Global Change

514 Biology 20, 2518 - 2530. doi: 10.1111/gcb.12590

515 Wang X., Thompson D.K., Marshall G.A., Tymstra C., Carr R., Flannigan M.D. (2015)

516 Increasing frequency of extreme fire weather in Canada with climate change. Climatic

$517 \quad$ Change 130, 573 - 586. doi: 10.1007/s10584-015-1375-5

518 Wang X., Parisien M-A., Taylor S.W., Perrakis D.D.B., Little J., Flannigan M.D. (2016) Future

519 burn probability in south-central British Columbia. Int. J. Wildland Fire 25, 200-212.

520 doi:10.1071/WF15091Ward J.H. (1963) Hierarchical grouping to optimize an objective

521 function. J. Am. Stat. Assoc. 58, $236-244$.

522 Wang, X., Wotton, M., Cantin, A., Parisien, M-A, Anderson, K., Moore, B., Flannigan, M.D.

523 2017. An R package for the Canadian Forest Fire Danger Rating System. Ecological

$524 \quad$ Processes. 6:5. DOI 10.1186/s13717-017-0070-z.

525

526 Wotton B.M., Martell D.L., Logan K.A. (2003) Climate change and people-caused forest fire 527 occurrence in Ontario. Climatic Change 60, 275 - 295.

528 Wotton B.M. (2009) Interpreting and using outputs from the Canadian Forest Fire Danger Rating

529 System in research applications. Environ. Ecol. Stat. 16, 107-131. doi: 10.1007/s10651-

$530 \quad$ 007-0084-2

531

532

533 Tables

$534 \quad$ Table 1: Parameters used for correlation and forecast evaluation. 
535 Thresholds for FFMC, ISI, and FWI are based on Taylor and Alexander (2006), Wang et al.

536 (2014b), and Podur and Wotton (2011), respectively. $e$-folding times for FFMC and FWI are

537 based on San-Miguel-Ayanz et al. (2003) and personal correspondence with Mike Wotton,

538 respectively. The $e$-folding time for ISI equals that for FFMC, since ISI is based only on FFMC

539 and the current day's wind speed. For each dependent variable, maximum time lag is the

540 greatest lag $k$ such that $w_{k}$ (the weight in Equation 4 of supplementary material) is non-negligible

541 (order of $10^{-3}$ or greater).

\begin{tabular}{|l|l|l|l|}
\hline Dependent Variable & \multicolumn{1}{|c|}{$\begin{array}{c}\text { Extreme-value } \\
\text { Threshold }\end{array}$} & $\begin{array}{c}\text { Maximum Time Lag } \\
\text { (days) }\end{array}$ & $\begin{array}{c}e \text {-Folding Time } \\
\text { (hours) }\end{array}$ \\
\hline FFMC & 91 & 6 & 16 \\
\hline ISI & 8.7 & 6 & 16 \\
\hline FWI & 19 & 9 & 24 \\
\hline
\end{tabular}

542

Table 2: Controlled parameters (used for training and clustering).

\begin{tabular}{|c|c|c|c|}
\hline $\begin{array}{c}\text { Training } \\
\text { Parameters }\end{array}$ & Possible Values & Chosen Value & Reason for Chosen Value \\
\hline $\begin{array}{l}\text { Dimensions of } \\
\text { neuron layer }\end{array}$ & $\begin{array}{l}M, N \text { (both positive } \\
\text { integers) }\end{array}$ & Automatic & $\begin{array}{l}\text { SOM_PAK determines the best } M \text { and } \\
N \text {, from number of neurons and ratio } \\
\text { between top two eigenvalues of } \\
\text { training data (Kohonen et al. 1996). }\end{array}$ \\
\hline $\begin{array}{l}\text { Initialization } \\
\text { method }\end{array}$ & $\begin{array}{l}\text { Random, principal } \\
\text { components }\end{array}$ & $\begin{array}{l}\text { Principal } \\
\text { components }\end{array}$ & $\begin{array}{l}\text { Map types were initialized along the } \\
\text { first two principal components of the } \\
\text { training data. This leads to a better fit, } \\
\text { reducing epochs needed for rough- and } \\
\text { fine-tuning. }\end{array}$ \\
\hline $\begin{array}{l}\text { Number of } \\
\text { neurons }\end{array}$ & Positive integer & 5000 & $\begin{array}{l}\text { SOM performance increases with } \\
N_{\text {neurons }} \text { (Ultsch and Mörchen 2005). } \\
5000 \text { is a compromise between } \\
\text { performance and computing resources. }\end{array}$ \\
\hline $\begin{array}{l}\text { Shape of } \\
\text { neuron array }\end{array}$ & $\begin{array}{l}\text { Sheet, cylindrical, } \\
\text { toroidal }\end{array}$ & Rectangular & Easier to understand and visualize. \\
\hline $\begin{array}{l}\text { Topology of } \\
\text { neuron array }\end{array}$ & $\begin{array}{l}\text { Hexagonal, } \\
\text { rectangular }\end{array}$ & Hexagonal & $\begin{array}{l}\text { Easier to understand (each neuron has } \\
6 \text { equidistant neighbours, rather than } 4 \\
\text { edge neighbours and } 4 \text { corner } \\
\text { neighbours). }\end{array}$ \\
\hline Training mode & Batch, sequential & Batch & Decreases runtime. \\
\hline
\end{tabular}




\begin{tabular}{|c|c|c|c|}
\hline $\begin{array}{l}\text { Clustering } \\
\text { Parameters }\end{array}$ & & & \\
\hline $\begin{array}{l}\text { Training mode } \\
\text { (K-means only) }\end{array}$ & Batch, sequential & Batch & Decreases runtime. \\
\hline $\begin{array}{l}\text { Number of } \\
\text { epochs } \\
\text { (K-means only) }\end{array}$ & Positive integer & 500 & $\begin{array}{l}\text { To ensure convergence. If } K \text {-means } \\
\text { converges before } 500 \text { epochs, } \\
\text { algorithm stops. }\end{array}$ \\
\hline $\begin{array}{l}\text { Number of } \\
\text { iterations } \\
\text { (K-means only) }\end{array}$ & Positive integer & 20 & $\begin{array}{l}K \text {-means is non-deterministic, so we } \\
\text { use the best iteration. Results usually } \\
\text { do not improve after } 20 \text { iterations. }\end{array}$ \\
\hline $\begin{array}{l}\text { Linkage } \\
\text { method } \\
\text { (AHC only) }\end{array}$ & $\begin{array}{l}\text { Average, centroid, } \\
\text { complete, median, } \\
\text { single, Ward, } \\
\text { weighted }\end{array}$ & Ward & $\begin{array}{l}\text { Ward's is the only method that we had } \\
\text { time to generalize from Euclidean to } \\
\text { gradient distance. }\end{array}$ \\
\hline
\end{tabular}

Table 3: Experimental parameters (used for training and clustering).

\begin{tabular}{|c|c|c|c|}
\hline Parameter & \multicolumn{2}{|c|}{ Values Tested } & Explanation (if necessary) \\
\hline $\begin{array}{l}\text { Number of } \\
\text { epochs }\end{array}$ & \multicolumn{2}{|c|}{$d=25,50,75,100$} & $\begin{array}{l}d \text { is a coefficient, used in Equations } 3 \text { to determine the } \\
\text { number of epochs. }\end{array}$ \\
\hline $\begin{array}{l}\text { Neighbourhood } \\
\text { function }\end{array}$ & \multicolumn{2}{|c|}{$\begin{array}{l}\text { Bubble, Gaussian, } \\
\text { bubble-Gaussian, } \\
\text { Epanechnikov }\end{array}$} & See Equation 2 in supplementary material. \\
\hline \multirow{4}{*}{$\begin{array}{l}\text { Neighbourhood } \\
\text { radius }\end{array}$} & $c_{1}=1 / 2$ & $c_{2}=1 / 2$ & \multirow{4}{*}{$\begin{array}{l}c_{1} \text { and } c_{2} \text { are coefficients, used in Equations } 4 \text { to } \\
\text { determine the initial neighbourhood radii for both } \\
\text { rough- and fine-tuning. }\end{array}$} \\
\hline & $c_{1}=1 / 2$ & $c_{2}=1 / 4$ & \\
\hline & $c_{1}=1 / 4$ & $c_{2}=1 / 2$ & \\
\hline & $c_{1}=1 / 4$ & $c_{2}=1 / 4$ & \\
\hline $\begin{array}{l}\text { Exponent in } \\
\text { gradient distance } \\
(L)\end{array}$ & \multicolumn{2}{|c|}{$1.0,1.5,2.0$} & See Equation 3 in supplementary material. \\
\hline $\begin{array}{l}\text { Clustering } \\
\text { method }\end{array}$ & \multicolumn{2}{|c|}{$K$-means, AHC } & $\begin{array}{l}\text { Main difference is that } \mathrm{AHC} \text { ( } K \text {-means) is } \\
\text { (non-)deterministic. }\end{array}$ \\
\hline $\begin{array}{l}\text { Number of } \\
\text { clusters } \\
\text { (final map types) }\end{array}$ & \multicolumn{2}{|c|}{$20,40,60,80,100$} & \\
\hline
\end{tabular}

548 AUC values are a $95 \%$ confidence interval over 100 bootstrap replicates. $d, c_{1}, c_{2}$, and $L$ have the

549 same meaning as in Table 4.

\begin{tabular}{|l|l|l|l|l|l|l|l|l|l|l|}
\hline Variable & Month & AUC & $\begin{array}{c}\text { Neigh } \\
\text { Months }\end{array}$ & $d$ & $L$ & $\begin{array}{c}\text { Neigh } \\
\text { Func'n }\end{array}$ & $c_{1}$ & $c_{2}$ & $\begin{array}{c}\text { Clust } \\
\text { Method }\end{array}$ & $\begin{array}{c}\text { Map } \\
\text { Types }\end{array}$ \\
\hline
\end{tabular}




\section{0}

551

552 For number of epochs, also experiment with other values as time allows.

\begin{tabular}{|l|l|l|l|}
\hline \multicolumn{1}{|c|}{ Parameter } & \multicolumn{1}{c|}{ Dependent Variable } \\
\hline \multicolumn{1}{|c|}{ FFMC } & \multicolumn{1}{c|}{ ISI } & \multicolumn{1}{c|}{ FWI } \\
\hline Number of epochs & $d \leq 25$ & $d \leq 50$ & $d \leq 25$ \\
\hline Neigh function & Try all functions. \\
\hline Neigh radius & Try all combinations of $c_{1}$ and $c_{2}$. \\
\hline Exponent in distance metric $(L)$ & Try 1.5 and 2.0. \\
\hline Clustering method & K-means & $\geq 60$ & $\leq 20$ \\
\hline Number of clusters (final map types) & $\leq 20$ & \\
\hline
\end{tabular}

\section{Table 5: Recommended values for experimental parameters.}

\begin{tabular}{|l|l|l|l|l|l|l|l|l|l|l|}
\hline & & & Used? & & & & & & & \\
\hline FFMC & May & {$[0.779,0.787]$} & no & 75 & 1.5 & bubble & $1 / 4$ & $1 / 2$ & $K$-means & 20 \\
& Jun & {$[0.735,0.743]$} & yes & 50 & 2.0 & bubble & $1 / 2$ & $1 / 2$ & $K$-means & 20 \\
& Jul & {$[0.773,0.790]$} & no & 50 & 1.5 & bubble & $1 / 2$ & $1 / 2$ & $K$-means & 20 \\
& Aug & {$[0.829,0.845]$} & no & 25 & 1.0 & Gauss & $1 / 4$ & $1 / 4$ & AHC & 60 \\
\hline ISI & May & {$[0.763,0.774]$} & no & 25 & 1.5 & Gauss & $1 / 4$ & $1 / 2$ & $K$-means & 40 \\
& Jun & {$[0.730,0.737]$} & yes & 25 & 1.5 & bubble & $1 / 2$ & $1 / 4$ & $K$-means & 60 \\
& Jul & {$[0.758,0.771]$} & no & 25 & 1.0 & Gauss & $1 / 4$ & $1 / 4$ & AHC & 60 \\
& Aug & {$[0.794,0.810]$} & no & 25 & 1.5 & Gauss & $1 / 4$ & $1 / 2$ & $K$-means & 40 \\
\hline FWI & May & {$[0.777,0.787]$} & no & 100 & 1.5 & Gauss & $1 / 2$ & $1 / 2$ & AHC & 40 \\
& Jun & {$[0.710,0.717]$} & yes & 25 & 2.0 & bubble & $1 / 4$ & $1 / 4$ & $K$-means & 60 \\
& Jul & {$[0.712,0.722]$} & no & 25 & 1.0 & Gauss & $1 / 4$ & $1 / 4$ & AHC & 60 \\
& Aug & {$[0.718,0.725]$} & yes & 25 & 2.0 & bubble & $1 / 4$ & $1 / 2$ & $K$-means & 60 \\
\hline
\end{tabular}




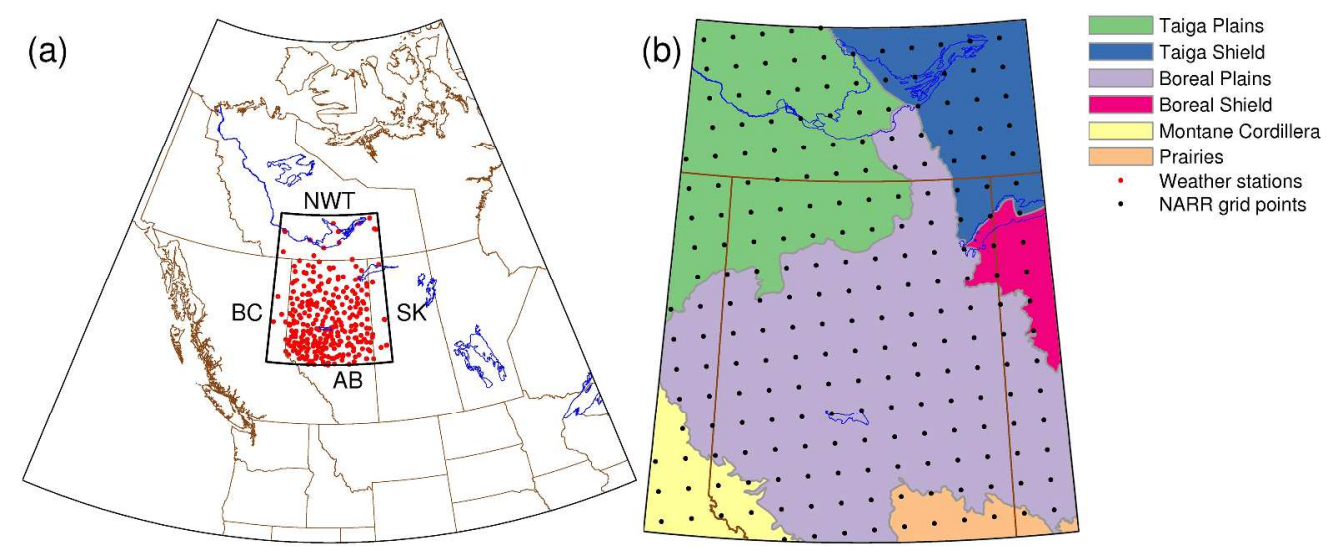

FIG. 1. [a] Location of study area and weather stations used for CFWIS indices. [b] Ecozones in study area and grid points used for predictor fields. AB, BC, and SK are the Canadian provinces of Alberta, British Columbia, and Saskatchewan respectively. NWT is the Canadian Northwest Territories.

$2001 \times 818 \mathrm{~mm}(72 \times 72$ DPI $)$ 

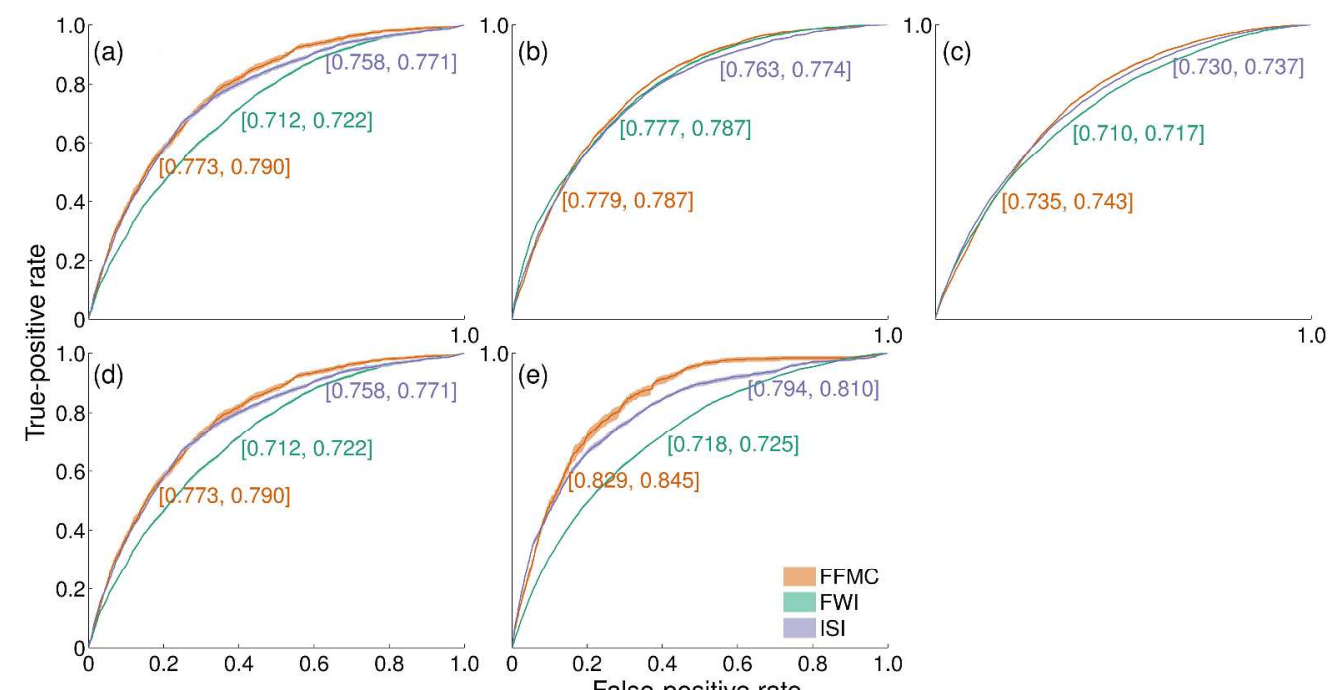

FIG. 2. Best ROC curves for different months and phases of tuning experiment. In each case the solid line (shading) shows the mean ( $95 \%$ confidence interval) over 100 bootstrap replicates. The $95 \%$ confidence interval for AUC is marked next to each ROC curve. [a] Phase 1. [b] Phase 2, May. [c] Phase 2, June. [d] Phase 2, July. [e] Phase 2, August.

$$
2835 \times 1507 \mathrm{~mm} \text { (72 x } 72 \text { DPI) }
$$




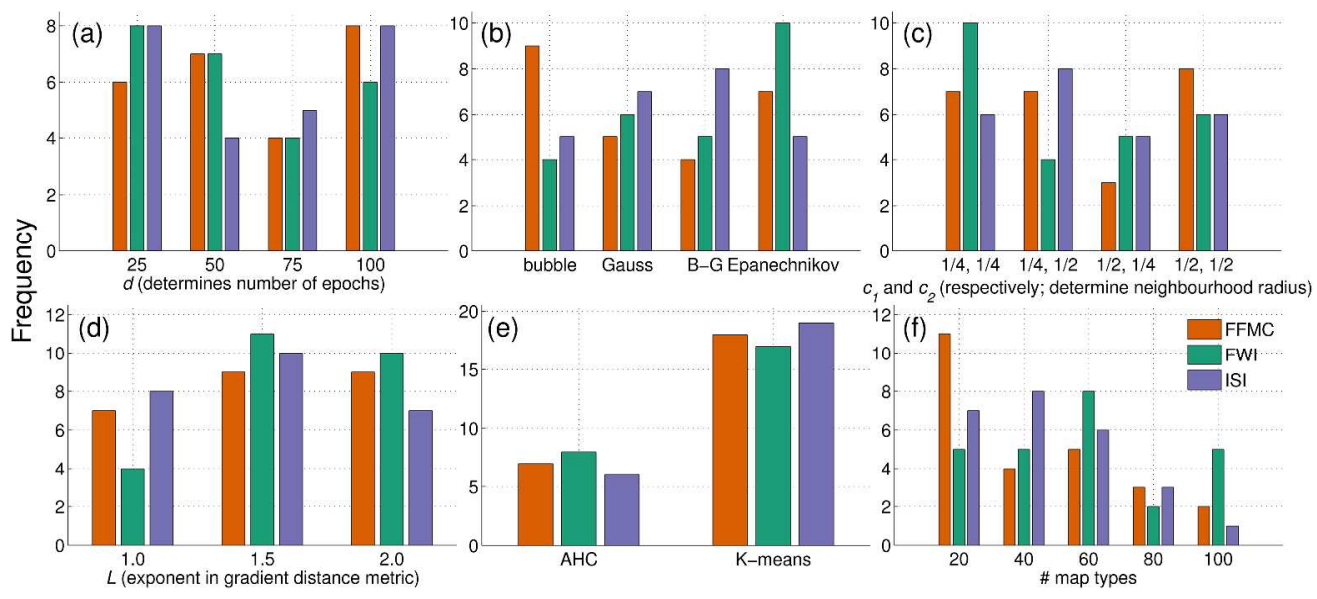

FIG. 3. For each dependent variable, bar graphs show the distribution of experimental parameters from the top 25 SOMs in Phase 1.

$2741 \times 1219 \mathrm{~mm}$ (72 x 72 DPI) 


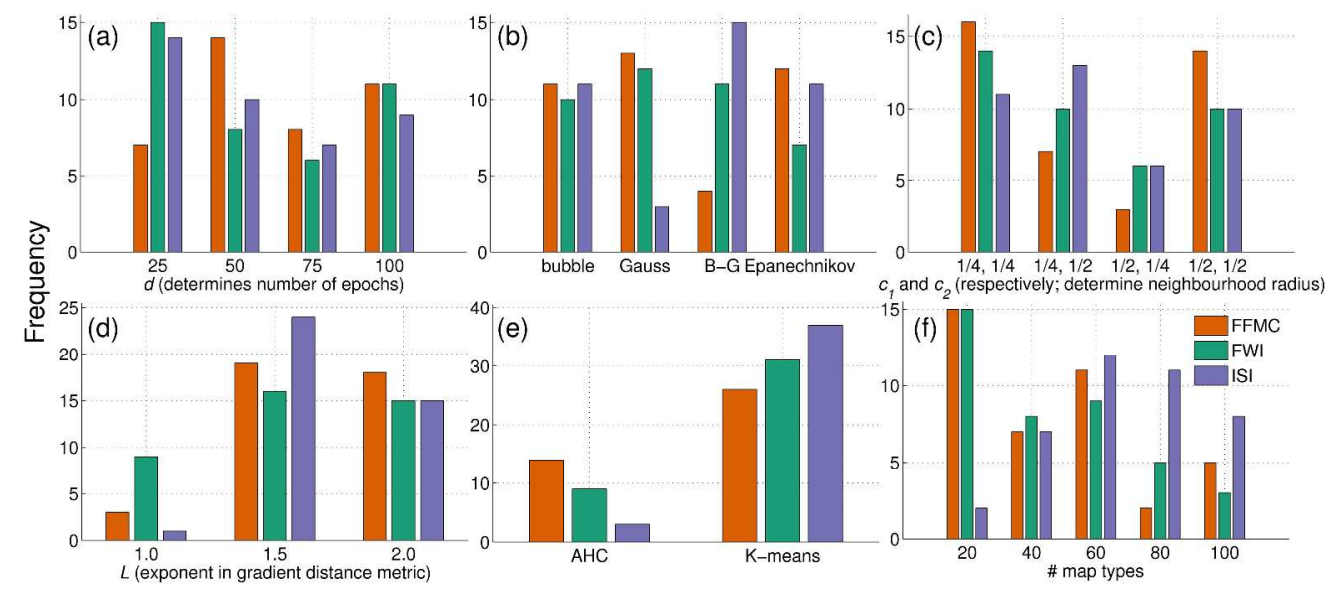

FIG. 4. Same as Fig. 4, except for Phase 2.

$2760 \times 1213 \mathrm{~mm}(72 \times 72 \mathrm{DPI})$ 


\section{Automated prediction of extreme fire weather from synoptic patterns in northern Alberta,}

\section{Canada. - Supplement}

Ryan Lagerquist ${ }^{1}$, Mike D. Flannigan ${ }^{2}$, Xianli Wang ${ }^{3}$, Ginny A. Marshall ${ }^{2}$

${ }^{1}$ School of Meteorology, University of Oklahoma, Norman, Oklahoma, United States, 73019

${ }^{2}$ Department of Renewable Resources, University of Alberta, Edmonton, Alberta, Canada T6G 2H1

${ }^{3}$ Canadian Forest Service, Great Lakes Forestry Center, Sault Ste. Marie, Ontario, Canada P6A $2 \mathrm{E} 5$

\section{Using SOMs to predict extreme fire weather: framework}

\subsection{Training the SOM}

SOMs were trained with the SOM_PAK toolbox for MATLAB (Kohonen et al. 1996). Training was done in two stages, rough-tuning and fine-tuning. Each stage consists of multiple epochs. During an epoch, each training example (predictor field) is presented to the SOM once. For each epoch $t$ and training example $i$, all neurons $j$ are updated by the following equation.

$$
\overrightarrow{M T_{J}} \leftarrow \overrightarrow{M T_{J}}+f_{n e i g h}\left(\sigma,\left\|\overrightarrow{r_{n *}}-\overrightarrow{r_{J}}\right\|\right)\left[\overrightarrow{x_{l}}-\overrightarrow{M T_{J}}\right]
$$

$\overrightarrow{M T_{J}}$ is the map type for the $j^{\text {th }}$ neuron; $f_{\text {neigh }}\left(\sigma,\left\|\overrightarrow{r_{n *}}-\overrightarrow{r_{j}}\right\|\right)$ is the neighbourhood function; $\sigma$ is the neighbourhood radius; $n^{*}$ is the winner neuron (that whose map type is most similar to $\overrightarrow{x_{l}}$ ); $\left\|\overrightarrow{r_{n *}}-\overrightarrow{r_{J}}\right\|$ is the distance in map space between the winner neuron and $j^{\text {th }}$ neuron; and $\overrightarrow{x_{l}}$ is the $i^{\text {th }}$ training example. 
The neighbourhood function determines the update weight for each neuron $j$, based on its distance from the winner neuron $n^{*}$ in map space (i.e., the Euclidean distance between the positions of neurons $j$ and $\left.n^{*}\right)$. Neurons closer to $n^{*}$ are given a higher update weight, so their map types are adjusted more strongly towards the training example. Meanwhile, the neighbourhood radius is the distance from $n^{*}$ at which the neighbourhood function drops to zero (or a very small value, if the neighbourhood function is Gaussian). Throughout both rough- and fine-tuning, the neighbourhood radius decreases to 1 , so that only $n^{*}$ and its immediate neighbours are updated.

As a concrete example, the Gaussian neighbourhood function is as follows. The meaning of each variable is the same as in Equation 1.

$$
f_{\text {neigh }}\left(\sigma,\left\|\overrightarrow{r_{n *}}-\overrightarrow{r_{j}}\right\|\right)=\exp \left(-\frac{\left\|\overrightarrow{r_{n *}}-\overrightarrow{r_{j}}\right\|}{2 \sigma^{2}(t)}\right)
$$

During rough-tuning, the neighbourhood radius is larger; thus, the SOM is more sensitive and requires fewer epochs to learn patterns in the training data. During fine-tuning, the neighbourhood radius is smaller, so the SOM is less sensitive and needs more epochs. The twostage training method reduces the risk of overfitting, as fine-tuning only may fit the SOM to noise in the training data.

As per Equation 1, the winner neuron (that with the most similar map type) must be found for each training example. Usually this is the map type with the minimum Euclidean distance from the training example. However, we defined a new distance function, called the "gradient distance," which accounts for the fact that vector fields are being compared rather than scalar fields. In experiments (not shown), SOMs performed much better when trained with the gradient distance. The following equation compares gradient vectors for one variable at one grid cell. 


$$
d\left(\vec{\nabla} x_{1}, \vec{\nabla} x_{2}\right)=\left[1-\sin \left(\theta_{1}\right) \sin \left(\theta_{2}\right)-\cos \left(\theta_{1}\right) \cos \left(\theta_{2}\right)\right]\left[\left\|\vec{\nabla} x_{1}\right\|^{L}+\left\|\vec{\nabla} x_{2}\right\|^{L}\right]
$$

$x$ is the relevant variable (SLP or H500); $\theta$ is the orientation of the gradient vector; $\sin \left(\theta_{1}\right) \sin \left(\theta_{2}\right)+\cos \left(\theta_{1}\right) \cos \left(\theta_{2}\right)$ is the dot product between gradient vectors [thus, $1-\sin \left(\theta_{1}\right) \sin \left(\theta_{2}\right)-\cos \left(\theta_{1}\right) \cos \left(\theta_{2}\right)$ is the difference between gradient directions]; $\|\vec{\nabla} x\|$ is the gradient magnitude; and $L$ is an arbitrary exponent. If $L>1(L<1)$, differences between the gradient magnitudes (directions) are more heavily emphasized. The "gradient distance" between two predictor fields (e.g., a map type and training example) is the sum of Equation 3 over all variables and grid cells.

\subsection{Clustering the SOM}

Following Ultsch and Mörchen (2005), we used a very large number of map types, then grouped similar map types into clusters. We used one of two clustering algorithms: either $K$ means (MacQueen 1967) or agglomerative hierarchical clustering (AHC) (Ward 1963). We used the gradient distance (Equation 3) to compare map types. After clustering, the mean of each cluster was computed; these means became the new map types. The number of original (clustered) map types was 5000 (20-100).

\subsection{Correlating the SOM}

Correlation and forecast evaluation (Section 1.4) require three input parameters for each dependent variable (FFMC, FWI, and ISI): the extreme-value threshold, $e$-folding time, and maximum time lag. Table 1 shows the values used.

SOM correlation involves creating a conditional climatology of the dependent variables for each map type. The procedure is described below for each map type $M$, dependent variable 
$V$, and grid cell $G$. Let $k_{\max }$ be the maximum time lag for $V$.

1. Find all training examples for which $M$ is the most similar map type.

2. For all such training examples and each time lag $k$ from $1 \ldots k_{\max }$ days, link all values of $V$ within $100 \mathrm{~km}$ of grid cell $G$ to map type $M$.

3. For each time lag $k$ from $1 \ldots k_{\text {max }}$ days, calculate the frequency of extreme $V$ within 100 km of $G$.

Since the distribution of weather stations does not match the $64-\mathrm{km}$ grid used for map types, a buffer distance was required to link map types and dependent variables spatially. As shown above, we chose a buffer distance of $100 \mathrm{~km}$. In experiments (not shown), SOM performance was similar for buffer distances of 50 and $200 \mathrm{~km}$. We chose $100 \mathrm{~km}$ subjectively, as this produced the easiest maps for us to interpret. The buffer distance could easily be changed, depending on users' needs.

\subsection{Forecast evaluation}

Evaluation consists of two steps: (a) predict dependent variables for test cases and (b) compare predictions with true values.

The following procedure was used to predict test cases for each dependent variable $V$, on date $D$ at grid cell $G$. Again, let $k_{\max }$ be the maximum time lag for $V$.

1. For each time lag $k$ from $1 \ldots k_{\max }$ days, find the most similar map type $\left(M_{k}\right)$ on date $D-k$.

2. For each time lag $k$ from $1 \ldots k_{\max }$ days, find the frequency of extreme $V$, within $100 \mathrm{~km}$ of grid cell $G$, under map type $M_{k}$. Let this frequency (calculated in Section 1.3) be $f_{k}$.

3. Combine all frequencies $f_{k}$ into a single value. This is done with an exponential 
weighting scheme:

$$
\begin{gathered}
\hat{p}_{\text {extreme }}=\frac{\sum_{k=1}^{k_{\max }} w_{k} f_{k}}{\sum_{k=1}^{k_{\max }} w_{k}} \\
w_{k}=\exp \left(-\frac{k-1}{\tau}\right)
\end{gathered}
$$

$k$ is the time lag (days); $k_{\max }$ is the maximum time lag for variable $V$ (days); $w_{k}$ is the weight for the $k^{\text {th }}$ time lag; $f_{k}$ is the frequency of extreme $V$ at time lag $k$; $\tau$ is the $e$-folding time for variable $V$ (days); and $\hat{p}_{\text {extreme }}$ is the resulting forecast. More specifically, this is the forecast probability of extreme $V$ on day $D$, within $100 \mathrm{~km}$ of grid cell $G$.

Once the above procedure has been repeated for each grid cell, a spatial map of the forecast probabilities can be produced. Figure S1 shows the forecast probabilities of extreme ISI at 0000 UTC 1 Jun 1995 (a test case, since 1995 was not used in training). This was during the historic Mariana Lake fire (around $56^{\circ} \mathrm{N}$ and $112^{\circ} \mathrm{W}$ ). The resulting forecast (panel $\mathrm{g}$ ) is close to the observed ISI field (panel $\mathrm{m}$ ).

\section{References}

Kohonen T., Hynninen J., Kangas J., Laaksonen J. (1996) SOM_PAK: The self-organizing map program package. Helsinki University of Technology, Laboratory of Computer and Information Science, Report A31.

MacQueen J. (1967) Some methods for classification and analysis of multivariate observations. Proceedings of the Fifth Berkeley Symposium on Mathematical Statistics and Probability. Vol. 1: Statistics, 281-297. 
Ultsch A., Mörchen F. (2005) 'ESOM-Maps: Tools for clustering, visualization, and classification with Emergent SOM.' Department of Mathematics and Computer Science, University of Marburg, Research Report 46. 


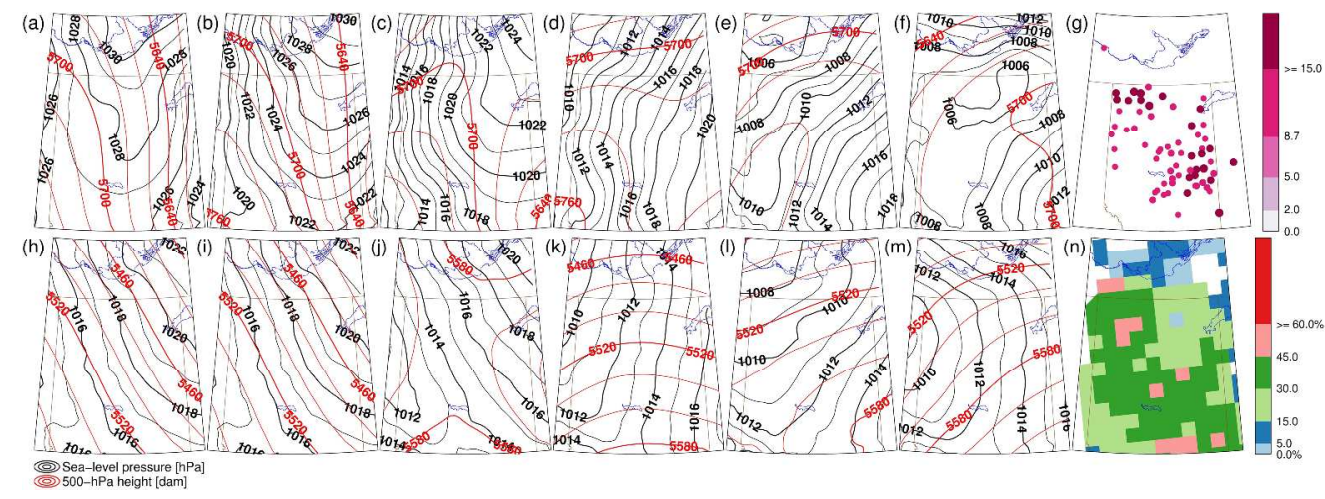

2694x990mm (72 x 72 DPI) 